\title{
Green Synthesis of Zinc Oxide Nanoparticles
}

Loaded on Activated Carbon Prepared From Walnut Peel Extract for the Removal of Eosin $Y$ and Erythrosine B Dyes From Aqueous Solution: Experimental Approaches, Kinetics Models and Thermodynamic Studies

\section{Yousef Rashtbari}

Ardabil University of Medical Sciences: Ardebil University of Medical Sciences

Shirin Afshin

Ardabil University of Medical Sciences: Ardebil University of Medical Sciences

Asghar Hamzezadeh

Ardabil University of Medical Sciences: Ardebil University of Medical Sciences

Abdolmajid Gholizadeh

North Khorasan University of Medical Sciences

Farshid Jaberi Ansari

Tehran University of Medical Sciences

\section{Yousef Poureshgh}

Ardabil University of Medical Sciences: Ardebil University of Medical Sciences mehdi fazlzadeh ( $\nabla$ m.fazlzadeh@gmail.com )

Ardabil University of Medical Sciences: Ardebil University of Medical Sciences https://orcid.org/00000001-9512-6025

\section{Research Article}

Keywords: Green synthesis, Adsorption, Nanoparticles, Dyes, Activated carbon

Posted Date: May 4th, 2021

DOl: https://doi.org/10.21203/rs.3.rs-427770/v1

License: (c) (1) This work is licensed under a Creative Commons Attribution 4.0 International License. Read Full License 
Version of Record: A version of this preprint was published at Environmental Science and Pollution Research on August 21st, 2021. See the published version at https://doi.org/10.1007/s11356-021-160067. 
Green synthesis of zinc oxide nanoparticles loaded on activated carbon prepared from walnut peel extract for the removal of Eosin $\mathrm{Y}$ and

3 Erythrosine B dyes from aqueous solution: Experimental approaches, kinetics models and thermodynamic studies

5 Yousef Rashtbari ${ }^{1,2}$, Shirin Afshin ${ }^{2}$, Asghar Hamzezadeh ${ }^{2}$, Abdolmajid Gholizadeh ${ }^{3}$, Farshid Jaberi Ansari ${ }^{4}$, Yousef Poureshgh ${ }^{2, *}$, Mehdi Fazlzadeh ${ }^{5, *}$

$7{ }^{1}$ Students Research Committee, Faculty of Health, Ardabil University of Medical Sciences, 8 Ardabil, Iran

$9{ }^{2}$ Department of Environmental Health Engineering, School of Health, Ardabil University of 10 Medical Sciences, Ardabil, Iran

$11{ }^{3}$ Department of Environmental Health Engineering, School of Public Health, North Khorasan 12 University of Medical Sciences, Bojnurd, Iran

$13{ }^{4}$ Department of medical nanotechnology, school of advanced technologies in medicine, Tehran 14 university of medical sciences, Tehran, Iran

$15{ }^{5}$ Department of Environmental Health Engineering, School of Public Health, Tehran University 16 of Medical Sciences, Tehran, Iran

\section{Corresponding authors:}

19 yusef.poureshg@gmail.com (Y. Poureshgh), m.fazlzadeh@gmail.com (M. Fazlzadeh) 


\section{Abstract}

29 Water contamination due to release of dye containing effluents is one of the environmental 30 problems of serious concern today. The present study investingate the Green synthesis of zinc 31 oxide nanoparticles ( $\mathrm{ZnO}-\mathrm{NPs})$ doped on activated carbon (AC) prepared from walnut peel extract 32 and to estimate its efficiency in the removal of Eosin Y (Eo-Y) and Erythrosine B (Er-B) from its 33 aqueous solution. The synthesized $\mathrm{AC}-\mathrm{ZnO}$ was identified by field emission scanning electron 34 microscopy (FE-SEM), X-ray diffraction (XRD) and the Brunauer-Emmett-Teller (BET). The 35 influence of various parameters such as $\mathrm{pH}$, dosage of $\mathrm{AC}-\mathrm{ZnO}$, contact time, and concentrations 36 of Eo-Y and Er-B were also studied. The pH 3 was observed as the optimum pH while the 37 equilibrium was noticed to reach in $30 \mathrm{~min}$ at dosage of $1 \mathrm{~g} / \mathrm{L}$ and initial concentration $100 \mathrm{mg} / \mathrm{L}$

38 for Eosin $\mathrm{Y}$ and Erythrosine B adsorption onto AC-ZnO. The maximum adsorption capacity of 39 Eo-Y and Er-B onto AC-ZnO was found to be 163.9 and $144.92 \mathrm{mg} / \mathrm{g}$ (and removal efficiencies 40 of 95.11 and $98.31 \%$ ), respectively. The process of Eo-Y and Er-B adsorption on AC-ZnO was 41 observed to be depended on the pseudo-second-order kinetic model which indicate chemisorption 42 processes. Langmuir adsorption isotherm model test described the removal of Eo-Y and Er-B on 43 AC-ZnO. The Eo-Y and Er-B adsorption were found to be non-spontaneous and endothermic in 44 nature. Also, the values, $\mathrm{S}_{\mathrm{BEt}}$ and $\mathrm{V}_{\text {TOTAL }}$ for the $\mathrm{AC}-\mathrm{ZnO}$ were equal to $725.65 \mathrm{~m}^{2} / \mathrm{g}$ and 0.6004 $45 \mathrm{~cm}^{3} / \mathrm{g}$, respectively. The results of this study exhibited that AC-ZnO was a very effective method 46 that can be used for the removal of Eo-Y and Er-B from aqueous solutions.

47 Keywords: Green synthesis. Adsorption. Nanoparticles. Dyes. Activated carbon Introduction

49 The textile industry uses high volumes of dyes and produces wastewaters containing these dyes at 50 a concentration range of $10-200 \mathrm{mg} / \mathrm{L}$ (Ahmadi et al. 2019b, Mendez-Paz et al. 2005). Studies 
51 have shown that most of them are toxic, allergens and mutants. These compounds provide negative

52 effects on the appearance and quality of water (Ghosh \&Bhattacharyya 2002, Zhang et al. 2005).

53 Eosin $\mathrm{Y}$ (Eo-Y) causes skin and eye irritation and reduces the respiratory capacity of the lungs

54 (Sun et al. 1987). Erythrosine B (Er-B) causes allergies, thyroid disorders, carcinogenesis and

55 DNA-linked behavioral disorders (Al-Degs et al. 2012, Gupta et al. 2006). Therefore, wastewaters

56 that contain the dyes, were underlined as one of the most significant threatening factor to the

57 environment and public health (Ahmadi et al. 2020a, Igwegbe et al. 2019b). Several approaches

58 has been implemented for the elimination of textile wastewaters, including the application of photo

59 decomposition (Dehghani et al. 2015, Tarkwa et al. 2019), ozone (Venkatesh \&Venkatesh 2020),

60 adsorption (Abdollahzadeh et al. 2020), advanced oxidation (Ahmadi et al. 2018, Ahmadi et al.

61 2020b), biodegradation (M-Ridha et al. 2020, Sonwani et al. 2020), electrocoagulation/flotation

62 (Chigozie \&Joseph 2014, Zodi et al. 2013), coagulation (Obiora-Okafo et al. 2020) and other

63 processes.

64 Adsorption process is a physical method in which natural or synthetic adsorbents are used to bleach

65 the colorful compounds (Baghapour et al. 2013, MALAKOOTIAN et al. 2016). Nano technology

66 provided a new field in the healthcare. Currently, nano technology is the crucial and effective

67 technology in science and industry (Ahmadi et al. 2020a). It helps to change the atoms and

68 molecules arrangement to achieve new structure which has never been existed before. Nano

69 technology has found many applications in water treatment including treatment of sewage and

70 industrial wastewaters, and the purification of air (Ahmadi et al. 2020a, Liu et al. 2019, Shi et al.

71 2019). Zinc oxide nanoparticles (ZnO-NPs) has been widely used in the removal of contaminants

72 due to their advantages such as high catalytic properties, non-toxicity and low cost (Ahmadi

73 \&Igwegbe 2020, Ansari et al. 2016). In most chemical methods, a chemical reducing agent has 
74 been used as a stabilizer to control particle growth and prevent aggregation. The demand for the

75 synthesis of environmentally friendly nano particles has been increased noticeably in the past two

76 decades. Various plants extracts and their products has been used as an alternative to the synthesis

77 of nanoparticles in biological methods (Fazlzadeh et al. 2017, Ramezani et al. 2013). On the other

78 hand, in order to accelerate the separation and stabilization of nanomaterials on materials such as

79 fillers, polymers, oxides, and activated carbon, it is necessary to use activated carbon which has

80 economic and environmental benefits (Fazlzadeh et al. 2017, Ghaedi et al. 2013). Ghaedi et al.

81 compared the efficiency of palladium, silver and zinc oxide nanoparticles fixed on active jelly

82 which has been used as an adsorbent to remove dye. In batch adsorption systems, adsorption of

83 adsorbate on adsorbent surface is monolayer adsorption and with increasing $\mathrm{pH}$ from 1 to 9 , the

84 adsorption of bromophenol red dye decreased from 250 to $142.8 \mathrm{mg} / \mathrm{g}$ (Ghaedi et al. 2013). The

85 study of Arabi et al. (Arabi et al. 2019) has showed that Congo red dye adsorption used activated

86 carbon coated with oxidized nanoparticles. The optimal conditions observed for dye removal are

87 contact time of $55 \mathrm{~min}$, dose $9 \mathrm{mg}$ and temperature $55^{\circ} \mathrm{C}$ that ensures efficiencies $>99.8 \%$. The

88 study data has also exhibited a quadratic reaction coefficient (Arabi et al. 2019).

89 The current study focused on the Green synthesis of Walnut peel extract zinc oxide $(\mathrm{ZnO})$ doped

90 activated carbon (AC) nanoparticles. The purity of the AC-ZnO was identified by scanning

91 electron microscopy (SEM), X-ray diffraction (XRD) and the Brunauer-Emmett-Teller (BET).

92 Further testing was also conducted in order to test efficiency of these nanoparticles in the removal

93 of Eosin $\mathrm{Y}(\mathrm{Eo}-\mathrm{Y})$ and Erythrosine B(Er-B) from their aqueous solution. Additionally, the

94 influence of various parameters such as contact time, adsorbent dosage of AC- $\mathrm{ZnO}, \mathrm{pH}$ and initial

95 concentrations of Eo-Y and Er-B were also being estimated in order to determine the optimum

96 conditions which will subsequently enhance the efficiency of the AC-ZnO in Eo-Y and Er-B 
97 removal. Finally, the kinetics, isotherm and thermodynamics of the adsorption process were also

98 studied.

99

100 Materials and methods

101 Chemicals

102 Eosin Y (Eo-Y) and Erythrosine B (Er-B) dye were used as the pollutant and purchased from 103 Alvan Sabet Corporation, Hamadan, Iran. All reagents were of analytical grade and purchased 104 from Merck (Germany). All solutions were prepared by using de-ionized water. The $\mathrm{pH}$ of the 105 solution was adjusted by adding $\mathrm{HCl}$ or $\mathrm{NaOH} 0.1 \mathrm{~N}$ solutions. The molecular structure of the Eo$106 \mathrm{Y}$ and Er-B is shown in Table 1.

Table 1.

108 Preparation of the active carbon

109 Worn tires were used to prepare activated carbon. Initially the tires were crushed to a size of 0.5

$110 \mathrm{~cm}$ and put in phosphoric acid. Following that, the tires were heated at a temperature of $800^{\circ} \mathrm{C}$ for

$1112 \mathrm{~h}$. The produced $\mathrm{AC}$ was washed with distilled water and dried in the oven at $110^{\circ} \mathrm{C}$ for a period

112 of $2 \mathrm{~h}$ (Fazlzadeh et al. 2017).

\section{ZnO preparation using green synthesis technique}

114 Walnut peel extract was prepared by boiling at $80{ }^{\circ} \mathrm{C}$ for $60 \mathrm{~min}$ followed by filtration. In order to 115 synthesize Zinc oxide nanoparticles ( $\mathrm{ZnO}-\mathrm{NPs}$ ), the $\mathrm{ZnCl}_{2}$ salt was mechanically blended with the 116 walnut shell in a ratio of 2:3. Following the filtration and drying at $70{ }^{\circ} \mathrm{C}$ for $24 \mathrm{~h}$, the blended 117 mixture was calcined for $2 \mathrm{~h}$ at $800^{\circ} \mathrm{C}$ (Fazlzadeh et al. 2017).

\section{Loading ZnO-NPs on AC}


119 Following the preparation of the AC, ZnO-NPs was sanitized. About $0.05 \mathrm{~g}$ of ZnO-NPs was added

120 separately into $250 \mathrm{~mL}$ of distilled water and the solution was homogenized on a magnetic mixer

121 for $20 \mathrm{~min}$. Following that, the solution was added to the $5 \mathrm{~g}$ of the AC and mechanically blend at

$122500 \mathrm{rpm}$ for $2 \mathrm{~h}$. Finally, the mixture was purified and the stock was repeatedly washed with clean

123 water, and finally dried for $12 \mathrm{~h}$ at $95^{\circ} \mathrm{C}$ (Fazlzadeh et al. 2017).

\section{Characterization of $\mathbf{A C}-\mathbf{Z n O}$}

125 field emission scanning electron microscopy (FE-SEM) was used to study the morphology of the 126 AC-ZnO nanoparticles by means of a HITACHI S-4160 instrument (Japan). XRD measurements 127 were performed on a Bruker (Model Inel diffractometer EQuniox 3000, USA) diffractometer with $1282 \theta$ radiation. The nitrogen adsorption isotherm was measured using Quantachrom ChemBET1293000 USA to observe the B.E.T. surface area $\left(\mathrm{S}_{\mathrm{BET}}\right)$ of the AC-ZnO.

130 Evaluation of zero charge point (pHpzc) for the AC-ZnO

131 To evaluate the $\mathrm{pH}_{\mathrm{pzc}}$ of the nanocomposite $\mathrm{AC}-\mathrm{ZnO}$, the electrolyte, sodium chloride $(\mathrm{NaCl})(0.1$ $132 \mathrm{mM}$ ) was introduced into Erlenmeyer flasks of $100 \mathrm{~mL}$, while $\mathrm{H}_{2} \mathrm{SO}_{4}$ and $\mathrm{NaOH}$ solutions were 133 used as $\mathrm{pH}$ control agents. Thereafter, $0.04 \mathrm{~g}$ of the $\mathrm{AC}-\mathrm{ZnO}$ was poured into various Erlenmeyer $134250 \mathrm{~mL}$ flasks, and the solution $\mathrm{pH}$ was balanced at $\mathrm{pHs} 2-12$ and blended at $250 \mathrm{rpm}$ for $48 \mathrm{~h}$. 135 Following this the pHs of the solutions was re-measured (Rivera-Utrilla et al. 2010).

\section{Batch adsorption studies}

137 The effects of different parameters such as $\mathrm{pH}$, contact time, pollutant concentration and adsorbent 138 dose were analyzed. At each adsorption test time, the specified volume of the Eo-Y and Er-B 139 solution with a definite concentration was added into the Erlenmeyer flask. The anticipated 140 conditions were set up and a certain dosage of adsorbent was added to the flask followed by 141 thorough mixing with the magnetic stirrer (MODEL: MSH basic) at $250 \mathrm{rpm}$. The initial and final 
142 Eo-Y and Er-B concentrations remaining in solutions were examined by a DR5000

143 spectrophotometer (Shimadzu Model: $\mathrm{HACH}{ }^{\circledR}$ ), USA at a wavelength of maximum absorbance,

$144 \lambda \lambda_{\max }=515$ and $527 \mathrm{~nm}$, respectively. The removal efficiency, R (\%) and the amount of Eo-Y and

145 Er-B adsorbed, qe $(\mathrm{mg} / \mathrm{g})$ of the studied parameters were calculated based on the following 146 formulas (Rashtbari et al. 2018, Shokoohi et al. 2018):

$147 \quad \% R=\frac{\left(C_{0}-C_{f}\right)}{C_{0}} 100$

148 Where, $\mathrm{C}_{0}$ and $\mathrm{C}_{\mathrm{f}}$ is the initial and final Eo- $\mathrm{Y}$ and Er-B concentration, respectively.

$149 \quad q_{e}=\frac{\left(C_{0}-C_{e}\right) V}{M}$

150 Where, $M$ is the mass of adsorbent $(\mathrm{g})$ and $V$ is the volume of the solution (L). $C_{0}$ and $C_{e}$ are the

151 initial and final equilibrium liquid phase concentration of Eo-Y and Er-B dyes (mg/g),

152 respectively.

153 Results and discussion

154 Characterization of AC-ZnO

155 Fig. $1 \mathrm{~A}$ indicated that the AC was loaded with $\mathrm{ZnO}$ NPs. The XRD peaks showed the relative 156 broad nature of the AC- $\mathrm{ZnO}$ because of the presence of small sized AC particles. The porosity of 157 the $\mathrm{AC}-\mathrm{ZnO}$ and $\mathrm{AC}$ were observed by the total pore volume determination technique. The 158 mesoporosity of the AC-ZnO also determined. Fig.1 B exhibited the $\mathrm{N}_{2}$ adsorption-desorption 159 isotherms and pore size distribution of $\mathrm{AC}-\mathrm{ZnO}$ and $\mathrm{AC}$ at $1-0$ pressure range. The results revealed 160 that the $\mathrm{AC}-\mathrm{ZnO}$ and $\mathrm{AC}$ belongs to type IV isotherm and $\mathrm{H}_{2}$ type hysteresis loop. This type of 161 loop is assumed to be frequently caused by agglomerates of spherical particles of uneven size and 162 arrangements (Adelkhani et al. 2011). The B.E.T. specific surface area (S $\mathrm{SET})$, micropore specific 163 surface area $\left(\mathrm{S}_{\text {micro }}\right)$, mesoporous specific surface area $\left(\mathrm{S}_{\text {meso }}\right)$, total pore volume $\left(\mathrm{V}_{\text {Total }}\right)$, micropore 
164 volume ( $\left.\mathrm{V}_{\text {micro }}\right)$ and mesopore volume ( $\left.\mathrm{V}_{\text {meso }}\right)$ of the $\mathrm{AC}$ and $\mathrm{AC}-\mathrm{ZnO}$ have been compiled in Table

165 2. The parameters, $\mathrm{S}_{\mathrm{BET}}, \mathrm{S}_{\text {micro, }}, \mathrm{V}_{\text {Total }}, \mathrm{V}_{\text {micro, }}$ and $\mathrm{V}_{\text {meso }}$ presented for AC were improved after the

$166 \mathrm{ZnO}$ particles was loaded on the AC to give a better adsorbent. The results obtained showed that

167 the $\mathrm{S}_{\mathrm{BET}}$ and total pure volume for the $\mathrm{AC}-\mathrm{ZnO}$ are $725.65 \mathrm{~m}^{2} / \mathrm{g}$ and $0.6004 \mathrm{~cm}^{3} / \mathrm{g}$ respectively

168 while for the AC alone were $721.19 \mathrm{~m}^{2} / \mathrm{g}$ and $0.534 \mathrm{~cm}^{3} / \mathrm{g}$. The AC-nZVI showed an average pore

169 diameter $\left(D_{p}\right)$ of $3.198 \mathrm{~nm}$, which can play a pivotal role in the adsorption properties. On the other

170 hand, the mesoporosity feature of materials allows easier penetration of pollutant ions into their

171 pores (Xiao et al. 2015). Figs 1 (C) explains the surface morphological characteristics of AC-ZnO

172 at 200kx magnification by field emission scanning electron microscopy (FE-SEM). Furthermore,

173 the image confirms the nanoscale nature of the AC-ZnO. The presence of high porosity and a

174 suitable high surface area (in relation to the irregularity of the $\mathrm{AC}-\mathrm{ZnO}$ ) was visualised. The pores

175 were also asymmetrically distributed.

\section{Fig. 1}

Table 2

\section{Effect parameters}

179 Results obtained by studding the $\mathrm{pH}$ effect on the adsorption efficiency of Eo-Y and Er-B on Nano-

180 composites are presented in Figs. 2 (A, B). The presented data in Fig. 2 (A) indicated that with

181 increasing of the $\mathrm{pH}$ from 3 to 9, the adsorption of Eo-Y and Er-B on Nano-composites surface

182 decreased. The rate of Eo-Y and Er-B removal on the nanocomposite at $\mathrm{pH} 3$ was at a maximum

183 rate. At $\mathrm{pH}<\mathrm{pH}_{\mathrm{pzc}}$, the $\mathrm{AC}-\mathrm{ZnO}$ had a positive charge and in $\mathrm{pH}>\mathrm{pH}_{\mathrm{pzc}}$, it had a negative charge.

184 As a result, for solutions with a $\mathrm{pH}<6.76$, the nanocomposite had a positive charge at its surface,

185 while the Er-B and Eo-Y dye molecules were negatively charged. As the $\mathrm{pH}$ decreases due to the

186 increase of ${ }^{+} \mathrm{H}$ ions in the solution and the formation of electrostatic attraction between the ${ }^{+} \mathrm{H}$ ion 
187 and the dye, the absorption rate increases. On the other hand, nanocomposite had a negative charge 188 due to $\mathrm{pH}>6.76$, so the anionic dye and the adsorbent repelled (Gupta et al. 2011) as also reported 189 by Carmen Apostol (Carmen Apostol et al. 2016). Fig. 2 B is the final pH of the Eo-Y and Er-B 190 solutions after Eo-Y and Er-B adsorption on the nanocomposite, AC-ZnO; linear effect was also 191 observed.

192 It is clear from the data (Fig. 2 C) that the amount of Eo-Y and Er-B from solution decreased as 193 the concentration of nanocomposite particles increased. Regarding this results, $1 \mathrm{~g} / \mathrm{L}$ absorbent 194 was determined as the optimal concentration. It is clear that increased absorbent particles 195 decreased the adsorption rate because of reducing adsorption surface and less availability to 196 adsorbents sites with increased particles. The percentage of adsorption was nearly fixed after the 197 adsorption sites was occupied reaching equilibrium (Carmen Apostol et al. 2016, Jamshidi et al. 198 2016). The result of this study is similar to Mouni et al. study of dye removal by kacain (Mouni et 199 al. 2018).

200 The results in Fig. 2 (D) highlight that the removal of Er-B and Fig. 2 (E) of Eo-Y decreased as a 201 function of contact time. The absorption rate at first was rapid and with time, the process became 202 slow until to saturation phase that lasted for 15 min. During the Er-B and Er-Y adsorption, the 203 surface of the nanocomposite was saturated by the Er-B and Er-Y molecules so it was impossible 204 to adsorb more adsorbate molecules with increasing concentration; this also led to rapid 205 equilibrium between the nanocomposite and the Er-B and Er-Y. This is because the number of 206 adsorbent particles that treated the fixed volume of liquid was constant even though the Er-B and 207 Er-Y concentrations were increased. In the initial moment of adsorption, more empty sites were 208 available, however, after a while, empty sites would be occupies as the adsorbed dyes molecules 
209 and the molecules which were in solution showed repulsion (Mahvi et al. 2020, Saif et al. 2012).

210 Similar result was reported by Regti et al. (Regti et al. 2017) and Ong et al. (Ong et al. 2007).

Fig 2 .

\section{Kinetics of adsorption and Studies of isotherm}

213 In order to further understand the adsorption process of Eo-Y and Er-B onto AC-ZnO

214 nanostructures, the kinetics of the process was investigated. The experimental kinetic data were

215 fitted into the Laguerre pseudo-first-order and Ho/Mckay pseudo-second-order kinetic models

216 (Ahmadi et al. 2019a, Ho \&McKay 1999, Lagergren \&Svenska 1898). The equations of linear

217 kinetic models with the description of the kinetic parameters are stated in Table 3. The linear

218 adsorption kinetics results obtained are presented in Table 4 . The agreement between the predicted

219 kinetic model values and the experimental data was confirmed by the regression coefficients $\left(\mathrm{r}^{2}\right)$.

220 It was detected that the pseudo-second-order kinetic model best described the kinetic experimental

221 data with its values of $r^{2}$ closer to unity. This means that the Eo-Y (0.998) and Er-B (0.999)

222 adsorption onto AC-ZnO is a chemical type of adsorption (Bagheri et al. 2017, Zhang et al. 2016).

223 Figs. 3 A-D show the typical equilibrium adsorption of Eo-Y and Er-B onto prepared AC-ZnO

224 nanostructures at $\mathrm{pH} 3, \mathrm{AC}-\mathrm{ZnO}$ nanostructures dosage of $1 \mathrm{~g} / \mathrm{L}$, Eo-Y and Er-B concentration of

$225100 \mathrm{mg} / \mathrm{L}$ and temperature of $289 \mathrm{~K}$. Study by Streit et al. (Streit et al. 2019) followed the pseudo-

226 second-order kinetic. Study by Afshin et al. (Afshina et al. 2019) is in similarity with this study.

227 The experimental kinetic data were fitted into the Langmuir and Freundlich models (Ahmadi

228 \&Igwegbe 2020, Eletta et al. 2020, Freundlich 1906, Langmuir 1918). With regards to the

229 correlation coefficients of the isotherm models (Table 5), the Eo-Y and Er-B adsorption

230 equilibrium data is more consistent with the Langmuir isotherm compared to the Freundlich 
231 isotherm. The results showed that the capacity of AC-ZnO for Eo-Y and Er-B $\left(q_{m}\right)$ was 163.93 and $232144.92 \mathrm{mg} / \mathrm{g}$, respectively.

\section{Table 3}

Table 4

\section{Fig. 3}

\section{Fig. 4}

\section{Table 5}

\section{Thermodynamic study}

239 The three basic parameters for thermodynamic study are standard enthalpy $\left(\Delta \mathrm{H}^{0}\right)$, Gibbs free 240 energy $\left(\Delta \mathrm{G}^{0}\right)$ and standard entropy $\left(\Delta \mathrm{S}^{0}\right)$. The free energy change can be determined by the 241 following equations (Balarak et al. 2016, Tan \&Sen 2020, Witek-Krowiak 2013):

$242 \Delta G^{0}=-R T \ln K$

243 Where $\Delta \mathrm{G}^{0}$ is the free energy change of sorption process $(\mathrm{kJ} / \mathrm{mol}), \mathrm{K}$ is the equilibrium constant,

$244 \mathrm{~T}$ is the temperature in $(\mathrm{K})$, and $\mathrm{R}$ is the universal gas constant $\left(8.314 \mathrm{~J} \mathrm{~mol}^{-1} \mathrm{~K}^{-1}\right)$. The free 245 energy change can be expressed in terms of enthalpy change of sorption as a function of 246 temperature as follows (BALARAK et al. 2020, Igwegbe et al. 2019a, Tan \&Sen 2020):

$247 \Delta \mathrm{G}^{0}=\Delta \mathrm{H}^{0}-\mathrm{T} \Delta \mathrm{S}^{0}$

$248 \quad \operatorname{Ln} K=-\frac{\Delta H^{0}}{R T}+\frac{\Delta S^{0}}{R}$

249 The $\Delta \mathrm{H}^{0}$ and $\Delta \mathrm{S}^{0}$ values were derived from linear plots of $\ln \mathrm{K}$ against $1 / \mathrm{T}$, which are the slope 250 and width of the graph linear equations, respectively. The thermodynamic parameters of Eo-Y 251 and Er-B adsorption on $\mathrm{AC}-\mathrm{ZnO}$ nanocomposites are shown in Table 6. The process of 252 adsorption of Eo-Y and Er-B by AC-ZnO was not spontaneous $(\Delta G>0)$. The non-spontaneity 253 was increased with rising temperature. The positive $\Delta H^{\circ}$ of adsorption reaction value (36.34 
$254 \mathrm{~kJ} / \mathrm{mol})$ showed that the process was endothermic $(\Delta H>0)$. Change in entropy $\left(\Delta S^{\circ}=-0.1264\right.$

$255 \mathrm{~kJ} / \mathrm{mol} . \mathrm{K}$ ) of Eo-Y and Er-B adsorption by $\mathrm{AC}-\mathrm{ZnO}$ is negative, indicating that the degree of

256 freedom at the stage of the solid solution reduces during adsorption (Acisli et al. 2020, Rahdar

257 et al. 2019, Tan \&Sen 2020).

\section{Table 6.}

259 Comparison of AC-ZnO nanocomposite for Eo-Y and Er-B removal with other adsorbents

260 The deposition of Eo-Y and Er-B on the composite AC-ZnO was compared with other adsorbents

261 (Table 7). In general, the results reported by the researchers shown in Table 7 demonstrated that

262 the various adsorbents could be integrated through the adsorption mechanism to extract Eo-Y and

263 Er-B with higher performance.

\section{Table 7}

\section{Adsorbent reclamation}

266 The adsorbent recovery process has been considered in order to get their economic value and solve

267 operational problems. As seen in Fig. 5, the performance was $93.44 \%$, which decreased to 81.74

$268 \%$ (five recovery cycles), suggesting that the restored adsorbent has a high potential to be used

269 regularly. Nanocomposite has a high potential for wastewater treatment in the pharmaceutical

270 industry. Because it can be reused after five consecutive periods by recovering the adsorbent and

271 by its ability to maintain the removal efficiency. It is also cost-effective and therefore very

272 necessary for industrial applications to prevent secondary pollution in the treatment of wastewater

273 (Chieng et al. 2015, Mansour et al. 2018).

Fig. 5

\section{Conclusions}


276 The investigational results obtained from application of AC-ZnO nanoparticles as adsorbent

277 showed that the maximum adsorption capacity of Eo-Y and Er-B onto AC-ZnO was 163.9 and

$278144.92 \mathrm{mg} / \mathrm{g}$ (and removal efficiencies of 95.11 and $98.31 \%$ ), respectively. This suggests the high

279 potential of adsorbing Eo-Y and Er-B by the prepared $\mathrm{AC}-\mathrm{ZnO}$ nanocomposite particles which

280 followed the pseudo-second-order kinetics and Langmuir isotherm models.

282 Availability of data and materials

283 The data used and analyzed during the current study are available from the corresponding author

284 upon reasonable request.

285 Consent to Participate

286 Not applicable.

287 Consent to Publish

288 All the authors agreed to publish the data in this journal.

289 Authors Contributions

290 Contributors: Yousef Poureshgh, Yousef Rashtbari and Mehdi Fazlzadeh participated in the 291 conceptualization and design of the research and supervised the work. Shirin Afshin and Asghar 292 Hamzezadeh are responsible for experimental analysis and interpretation of data. Abdolmajid 293 Gholizadeh and Farshid Jaberi Ansari contributed to literature search and quality assessment. All 294 authors have read and approved the final paper as submitted

295 Conflict of interest: The authors declare that there is no conflict of interest regarding the 296 publication of this manuscript

297 Ethical consideration: The protocol was approved by the Institutional Review Board of Ardabil 298 University of Medical Sciences (Approval ID: IR.ARUMS.REC.1398.015). 
Acknowledgments: This research work was financially supported by Ardabil University of

300 Medical Sciences; we gratefully acknowledge them.

301

302

303

304

305

306

307

308

309

310

\section{References}

Abdollahzadeh H, Fazlzadeh M, Afshin S, Arfaeinia H, Feizizadeh A, Poureshgh Y, Rashtbari Y (2020) Efficiency of activated carbon prepared from scrap tires magnetized by $\mathrm{Fe}_{3} \mathrm{O}_{4}$ nanoparticles: characterisation and its application for removal of reactive blue19 from aquatic solutions. International Journal of Environmental Analytical Chemistry, 1-15

Acisli O, Acar I, Khataee A (2020) Preparation of a fly ash-based geopolymer for removal of a cationic dye: Isothermal, kinetic and thermodynamic studies. Journal of Industrial and Engineering Chemistry 83, 53-63

Adelkhani H, Ghaemi M, Ruzbehani M (2011) Evaluation of the porosity and the nano-structure morphology of $\mathrm{MnO} 2$ prepared by pulse current electrodeposition. Int J Electrochem Sci 6, 123-35

Afshina S, Rashtbaria Y, Shirmardic M, Vosoughib M, Hamzehzadeha A (2019) Adsorption of Basic Violet 16 dye from aqueous solution onto mucilaginous seeds of Salvia sclarea: kinetics and isotherms studies. Desalination and water treatment 161, 365-75

Ahmadi S, Mohammadi L, Igwegbe CA, Rahdar S, Banach AM (2018) Application of response surface methodology in the degradation of Reactive Blue 19 using $\mathrm{H}_{2} \mathrm{O}_{2} / \mathrm{MgO}$ nanoparticles advanced oxidation process. International Journal of Industrial Chemistry 9 , 241-53

Ahmadi S, Igwegbe CA, Rahdar S, Asadi Z (2019a) The survey of application of the linear and nonlinear kinetic models for the adsorption of nickel(II) by modified multi-walled carbon nanotubes. Applied Water Science 9

Ahmadi S, Rahdar A, Rahdar S, Igwegbe CA (2019b) Removal of Remazol Black B from solution aqueous using $\mathrm{P}-\gamma-\mathrm{Fe}_{2} \mathrm{O}_{3}$ nanoparticles: synthesis, physical characterization, isotherm, kinetic and thermodynamic studies. Desalination and Water Treatment 152, 401-10

Ahmadi S, Igwegbe CA (2020) Removal of methylene blue on zinc oxide nanoparticles: nonlinear and linear adsorption isotherms and kinetics study. Sigma Journal of Engineering and Natural Sciences 38, 289-303

Ahmadi S, Mohammadi L, Rahdar A, Rahdar S, Dehghani R, Igwegbe CA, Kyzas GZ (2020a) Acid Dye Removal from Aqueous Solution by Using Neodymium(III) Oxide Nanoadsorbents. Nanomaterials (Basel) 10

Ahmadi S, Rahdar A, Igwegbe CA, Banach AM, Rahdar S, Singh AK, Rodriguez-Couto S, Kyzas GZ (2020b) Praseodymium-doped cadmium tungstate $\left(\mathrm{CdWO}_{4}\right)$ nanoparticles for dye degradation with sonocatalytic process. Polyhedron, 114792

Al-Degs YS, Abu-El-Halawa R, Abu-Alrub SS (2012) Analyzing adsorption data of erythrosine dye using principal component analysis. Chemical engineering journal 191, 185-94

Ansari F, Ghaedi M, Taghdiri M, Asfaram A (2016) Application of $\mathrm{ZnO}$ nanorods loaded on activated carbon for ultrasonic assisted dyes removal: experimental design and derivative spectrophotometry method. Ultrasonics sonochemistry 33, 197-209 
Arabi SMS, Lalehloo RS, Olyai MRTB, Ali GA, Sadegh H (2019) Removal of congo red azo dye from aqueous solution by $\mathrm{ZnO}$ nanoparticles loaded on multiwall carbon nanotubes. Physica E: Low-dimensional Systems and Nanostructures 106, 150-55

Baghapour MA, Jahed B, Joshani GH (2013) Preparation of activated carbon from waste tires and its application in gasoline removal from water. Iranian Journal of Health and Environment 6

Bagheri AR, Ghaedi M, Asfaram A, Bazrafshan AA, Jannesar R (2017) Comparative study on ultrasonic assisted adsorption of dyes from single system onto $\mathrm{Fe}_{3} \mathrm{O}_{4}$ magnetite nanoparticles loaded on activated carbon: experimental design methodology. Ultrasonics sonochemistry 34, 294-304

Balarak D, Mahdavi Y, Bazrafshan E, Mahvi AH, Esfandyari Y (2016) Adsorption of fluoride from aqueous solutions by carbon nanotubes: determination of equilibrium, kinetic, and thermodynamic parameters. Fluoride 49, 71

Balarak D, Chandrika K, Igwegbe Ca, Ahmadi S, Umembamalu Cj (2020) Biosorption Of Phenol Using Modified Barley Husk: Studies On Equilibrium Isotherm, Kinetics, And Thermodynamics Of Interactions. Sigma 38, 1161-77

Carmen Apostol L, Ghinea C, Alves M, Gavrilescu M (2016) Removal of Erythrosine B dye from water effluents using crop waste pumpkin seed hulls as adsorbent. Desalination and Water Treatment 57, 22585-608

Chatterjee S, Chatterjee S, Chatterjee BP, Das AR, Guha AK (2005) Adsorption of a model anionic dye, eosin $\mathrm{Y}$, from aqueous solution by chitosan hydrobeads. Journal of colloid and interface science $288,30-35$

Chieng HI, Lim LB, Priyantha N (2015) Sorption characteristics of peat from Brunei Darussalam for the removal of rhodamine B dye from aqueous solution: adsorption isotherms, thermodynamics, kinetics and regeneration studies. Desalination and Water Treatment 55, 664-77

Chigozie UF, Joseph NT (2014) Removal of Orange-G, Vat Yellow, Erythrosine dyes from synthetic wastewater by electrocoagulation and nanofiltration. J Adv Chem Eng 4, 2

Dehghani M, Taghizadeh MM, Gholami T, Ghadami M, Keshtgar L, Elhameyan Z, Javaheri MR, Shamsedini N, Jamshidi F, Shahsavani S (2015) Optimization of the parameters influencing the photo-Fenton process for the decolorization of Reactive Red 198 (RR198). Jundishapur J Health Sci 7, 38-43

Eletta OA, Adeniyi AG, Ighalo JO, Onifade DV, Ayandele FO (2020) Valorisation of Cocoa (Theobroma cacao) pod husk as precursors for the production of adsorbents for water treatment. Environmental Technology Reviews 9, 20-36

Elhami S, Abrishamkar M, Esmaeilzadeh L (2013) Preparation and Characterization of Diethylentriamine-montmorillonite and its application for the removal of Eosin Y dye: Optimization, Kinetic and Isotherm studies.

Fazlzadeh M, Khosravi R, Zarei A (2017) Green synthesis of zinc oxide nanoparticles using Peganum harmala seed extract, and loaded on Peganum harmala seed powdered activated carbon as new adsorbent for removal of $\mathrm{Cr}$ (VI) from aqueous solution. Ecological Engineering 103, 180-90

Freundlich H (1906) Over the adsorption in solution. J. Phys. Chem 57, 1100-07

Ghaedi M, Ghayedi M, Kokhdan SN, Sahraei R, Daneshfar A (2013) Palladium, silver, and zinc oxide nanoparticles loaded on activated carbon as adsorbent for removal of bromophenol red from aqueous solution. Journal of Industrial and Engineering Chemistry 19, 1209-17 
Ghosh D, Bhattacharyya KG (2002) Adsorption of methylene blue on kaolinite. Applied clay science 20, 295-300

Gupta V, Gupta B, Rastogi A, Agarwal S, Nayak A (2011) A comparative investigation on adsorption performances of mesoporous activated carbon prepared from waste rubber tire and activated carbon for a hazardous azo dye-Acid Blue 113. Journal of Hazardous Materials 186, 891-901

Gupta VK, Mittal A, Kurup L, Mittal J (2006) Adsorption of a hazardous dye, erythrosine, over hen feathers. Journal of colloid and interface science 304, 52-57

Ho Y-S, McKay G (1999) Pseudo-second order model for sorption processes. Process biochemistry 34, 451-65

Igwegbe C, Al-Rawajfeh A, Al-Itawi HI, Sharadqah S, Al-Qazaqi S, Abu Hashish E, Al-Qatatsheh M, Sillanpaa M (2019a) Utilization of Calcined Gypsum in Water and Wastewater Treatment: Removal of Phenol. Journal of Ecological Engineering 20, 1-10

Igwegbe CA, Mohmmadi L, Ahmadi S, Rahdar A, Khadkhodaiy D, Dehghani R, Rahdar S (2019b) Modeling of adsorption of Methylene Blue dye on Ho-CaWO4 nanoparticles using Response Surface Methodology (RSM) and Artificial Neural Network (ANN) techniques. MethodsX 6, 1779-97

Jamshidi M, Ghaedi M, Dashtian K, Ghaedi A, Hajati S, Goudarzi A, Alipanahpour E (2016) Highly efficient simultaneous ultrasonic assisted adsorption of brilliant green and eosin B onto $\mathrm{ZnS}$ nanoparticles loaded activated carbon: artificial neural network modeling and central composite design optimization. Spectrochimica Acta Part A: Molecular and Biomolecular Spectroscopy 153, 257-67

Lagergren S, Svenska B (1898) On the theory of so-called adsorption of materials, Royal Swed. Acad. Sci. Doc 24, 1-13

Langmuir I (1918) The adsorption of gases on plane surfaces of glass, mica and platinum. Journal of the American Chemical society 40, 1361403-

Liu Y, Huang Y, Xiao A, Qiu H, Liu L (2019) Preparation of magnetic $\mathrm{Fe}_{3} \mathrm{O}_{4} / \mathrm{MIL}-88 \mathrm{~A}$ nanocomposite and its adsorption properties for bromophenol blue dye in aqueous solution. Nanomaterials 9, 51

M-Ridha MJ, Hussein SI, Alismaeel ZT, Atiya MA, Aziz GM (2020) Biodegradation of reactive dyes by some bacteria using response surface methodology as an optimization technique. Alexandria Engineering Journal 59, 3551-63

Mahvi AH, Rahdar A, Igwegbe CA, Rahdar S, Ahmadi S (2020) Fluoride removal from aqueous solutions by zinc oxide nanoparticles. Fluoride

Malakootian M, Asadipour A, Mohammadi Ss (2016) A survey of the efficacy of calcium peroxide nanoparticles in the removal of reactive Red 198 from textile wastewater.

Manickam JR (2016) Study of water soluble dyes adsorption from aqueous solution by Prosopis spicigera L. wood (PSLW) carbon. Indian Journal of Chemical Technology (IJCT) 23, 2230

Mansour F, Al-Hindi M, Yahfoufi R, Ayoub GM, Ahmad MN (2018) The use of activated carbon for the removal of pharmaceuticals from aqueous solutions: a review. Reviews in Environmental Science and Bio/Technology 17, 109-45

Mendez-Paz D, Omil F, Lema J (2005) Anaerobic treatment of azo dye Acid Orange 7 under fedbatch and continuous conditions. Water research 39, 771-78

Mohebbi P, Parvini M, Mousav H (2014) Removal of erythrosine dyes from aquatic environment using Ziziphus nummularia kernel. Iran J Energy Environ 5, 400-06 
Mouni L, Belkhiri L, Bollinger J-C, Bouzaza A, Assadi A, Tirri A, Dahmoune F, Madani K, Remini H (201 (8Removal of Methylene Blue from aqueous solutions by adsorption on Kaolin: Kinetic and equilibrium studies. Applied Clay Science 153, 38-45

Obiora-Okafo I, Onukwuli O, Eli-Chukwu N (2020) Evaluation of bio-coagulants for colour removal from dye synthetic wastewater: characterization, adsorption kinetics, and modelling approach. Water SA 46, 300-12

Ong S, Lee C, Zainal Z (2007) Removal of basic and reactive dyes using ethylenediamine modified rice hull. Bioresource technology 98, 2792-99

Oyelude EO, Awudza JA, Twumasi SK (2017) Equilibrium, kinetic and thermodynamic study of removal of eosin yellow from aqueous solution using teak leaf litter powder. Scientific reports 7, 12198

Porkodi K, Kumar KV (2007) Equilibrium, kinetics and mechanism modeling and simulation of basic and acid dyes sorption onto jute fiber carbon: Eosin yellow, malachite green and crystal violet single component systems. Journal of hazardous materials 143, 311-27

Rahdar S, Taghavi M, Khaksefidi R, Ahmadi S (2019) Adsorption of arsenic (V) from aqueous solution using modified saxaul ash: isotherm and thermodynamic study. Applied Water Science 9, 87

Ramezani F, Kazemi B, Jebali A (2013) Biosynthesis of silver nanoparticles by Leishmania sp. New Cellular and Molecular Biotechnology Journal 3, 107-11

Rashtbari Y, Hazrati S, Afshin S, Fazlzadeh M, Vosoughi M (2018) Data on cephalexin removal using powdered activated carbon (PPAC) derived from pomegranate peel. Data in brief 20, 1434-39

Regti A, Laamari MR, Stiriba S-E, El Haddad M (2017) Use of response factorial design for process optimization of basic dye adsorption onto activated carbon derived from Persea species. Microchemical Journal 130, 129-36

Rivera-Utrilla J, Sánchez-Polo M, Prados-Joya G, Ferro-García M, Bautista-Toledo I (2010 ( Removal of tinidazole from waters by using ozone and activated carbon in dynamic regime. Journal of hazardous materials $174,880-86$

Saif MMS, Kumar NS, Prasad M (2012) Binding of cadmium to Strychnos potatorum seed proteins in aqueous solution: adsorption kinetics and relevance to water purification. Colloids and Surfaces B: Biointerfaces 94, 73-79

Shi X, Zhang S, Chen X, Mijowska E (2019) Evaluation of Nanoporous Carbon Synthesized from Direct Carbonization of a Metal-Organic Complex as a Highly Effective Dye Adsorbent and Supercapacitor. Nanomaterials 9, 601

Shokoohi R, Samadi MT, Amani M, Poureshgh Y (2018) Modeling and optimization of removal of cefalexin from aquatic solutions by enzymatic oxidation using experimental design. Brazilian Journal of Chemical Engineering 35, 943-56

Sonwani RK, Swain G, Giri BS, Singh RS, Rai BN (2020) Biodegradation of Congo red dye in a moving bed biofilm reactor: Performance evaluation and kinetic modeling. Bioresource Technology 302, 122811

Streit AF, Côrtes LN, Druzian SP, Godinho M, Collazzo GC, Perondi D, Dotto GL (2019) Development of high quality activated carbon from biological sludge and its application for dyes removal from aqueous solutions. Science of The Total Environment 660, 277-87

Sun JD, Henderson RF, Marshall TC, Cheng Y-S, Dutcher JS, Pickrell JA, Mauderly JL, Hahn FF, Banas DA, Seiler FA (1987) The inhalation toxicity of two commercial dyes: Solvent yellow 33 and solvent green 3. Fundamental and Applied Toxicology 8, 358-71 
Tan TCN, Sen TK (2020) Aqueous-phase methylene blue (MB) dye removal by mixture of eucalyptus bark (EB) biomass and kaolin clay (KC) adsorbents: kinetics, thermodynamics, and isotherm modeling. Separation Science and Technology 55, 1036-50

Tarkwa J-B, Oturan N, Acayanka E, Laminsi S, Oturan MA (2019) Photo-Fenton oxidation of Orange $\mathrm{G}$ azo dye: process optimization and mineralization mechanism. Environmental Chemistry Letters 17, 473-79

Venkatesh S, Venkatesh K (2020) Ozonation for degradation of acid red 14: effect of buffer solution. Proceedings of the National Academy of Sciences, India Section A: Physical Sciences 90, 209-12

Witek-Krowiak A (2013) Application of beech sawdust for removal of heavy metals from water: biosorption and desorption studies. European Journal of Wood and Wood Products 71, 227-36

Xiao J, Gao B, Yue Q, Gao Y, Li Q (2015) Removal of trihalomethanes from reclaimed-water by original and modified nanoscale zero-valent iron: characterization, kinetics and mechanism. Chemical Engineering Journal 262, 1226-36

Zhang H, Duan L, Zhang Y, Wu F (2005) The use of ultrasound to enhance the decolorization of the CI Acid Orange 7 by zero-valent iron. Dyes and pigments 65, 39-43

Zhang L, Hu P, Wang J, Huang R (2016) Adsorption of Amido Black 10B from aqueous solutions onto $\mathrm{Zr}$ (IV) surface-immobilized cross-linked chitosan/bentonite composite. Applied Surface Science 369, 558-66

Zodi S, Merzouk B, Potier O, Lapicque F, Leclerc J-P (2013) Direct red 81 dye removal by a continuous flow electrocoagulation/flotation reactor. Separation and Purification Technology 108, 215-22 
Figures
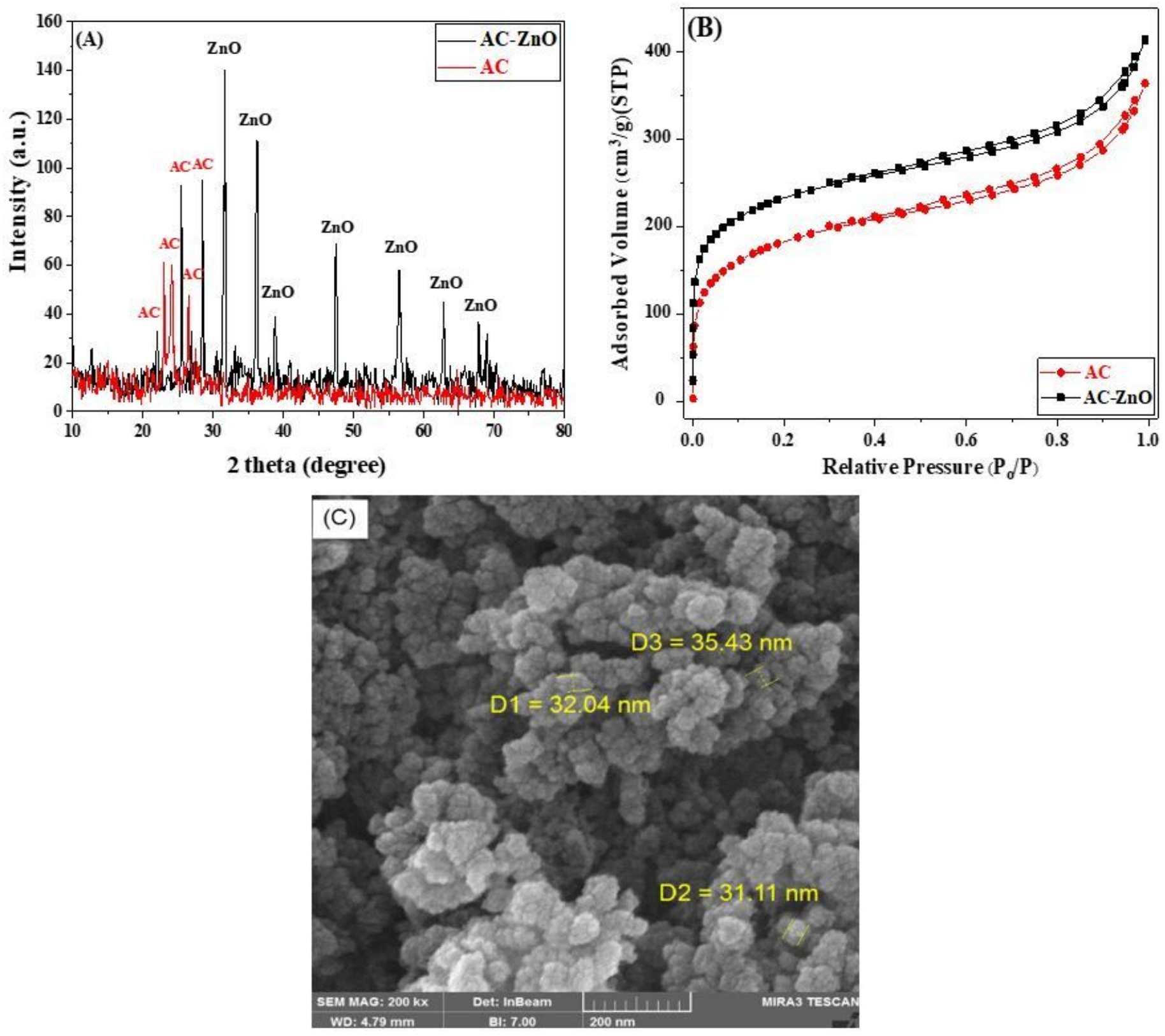

Figure 1

XRD pattern (A), N2 adsorption-desorption isotherm for AC- ZnO (B), FE-SEM images of the AC- ZnO (C) 

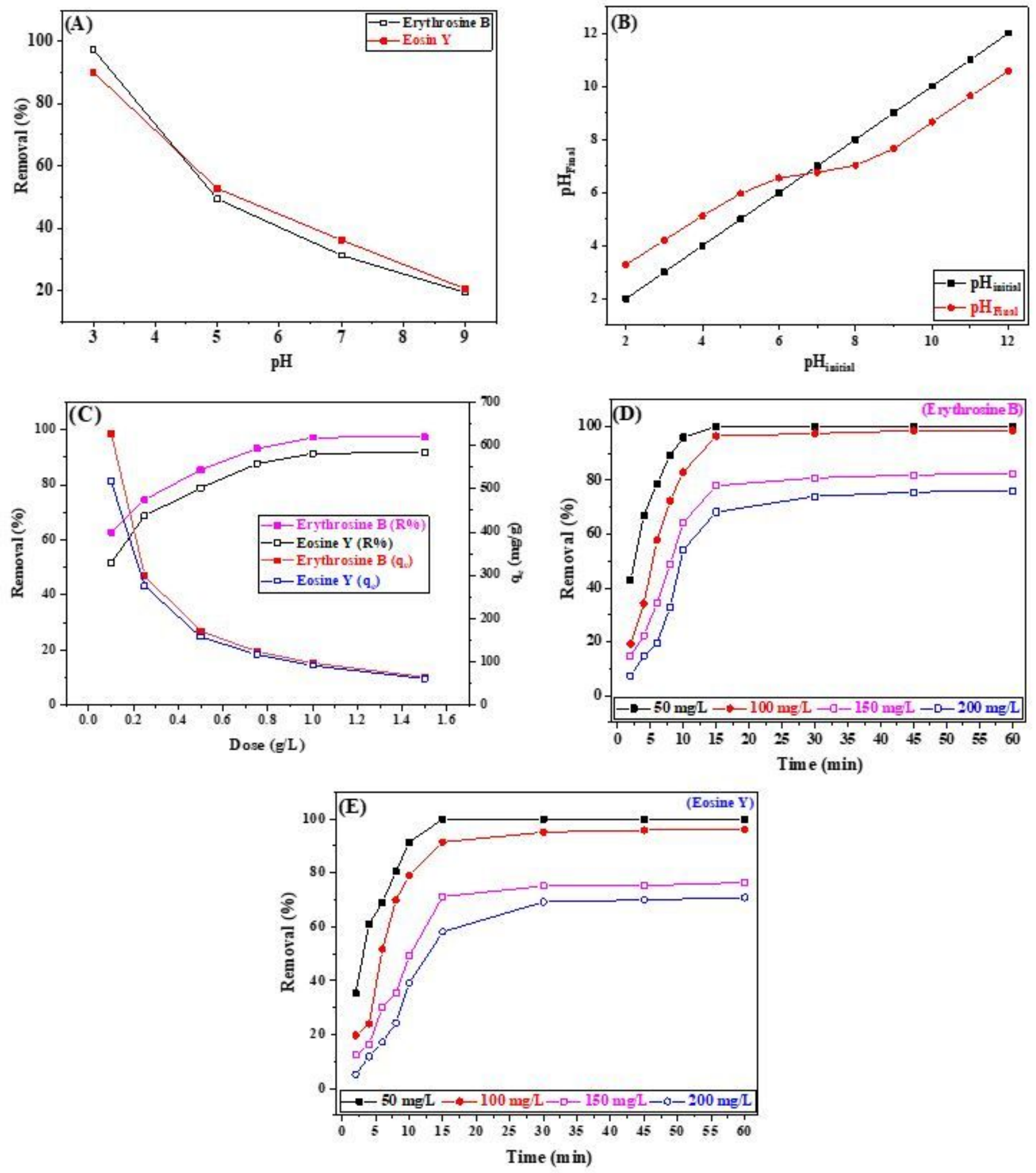

Figure 2

Effect of pH (A), AC- ZnO pHpzc (B), AC- ZnO dosage (C), contact time (D, E) on percentage removal of Eo$\mathrm{Y}$ and $\mathrm{Er}-\mathrm{B}$ 

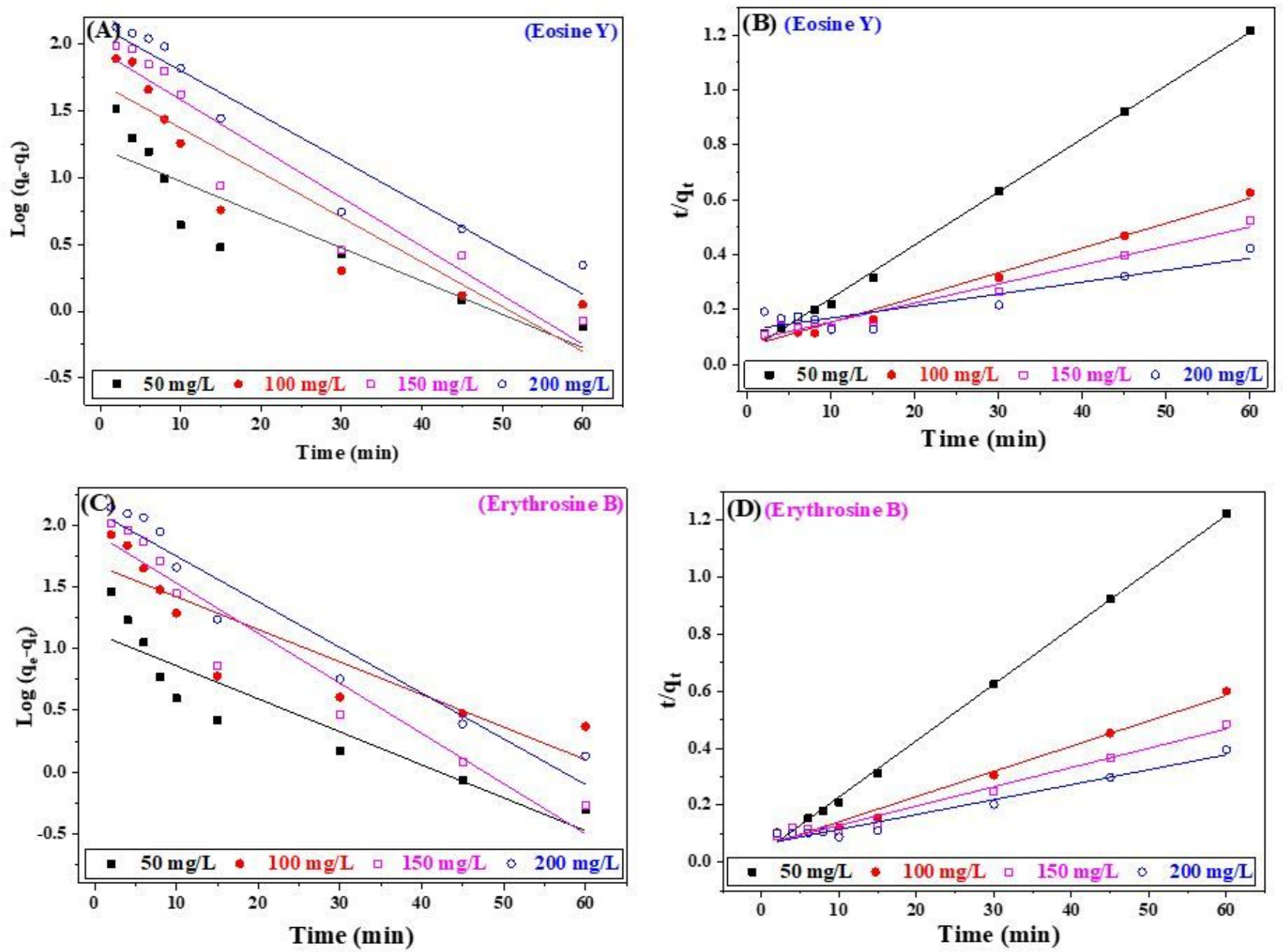

Figure 3

Pseudo-first-order (A, B) and pseudo-second-order (C, D) kinetics models for adsorption of Eo-Y and Er-B by AC-ZnO. 

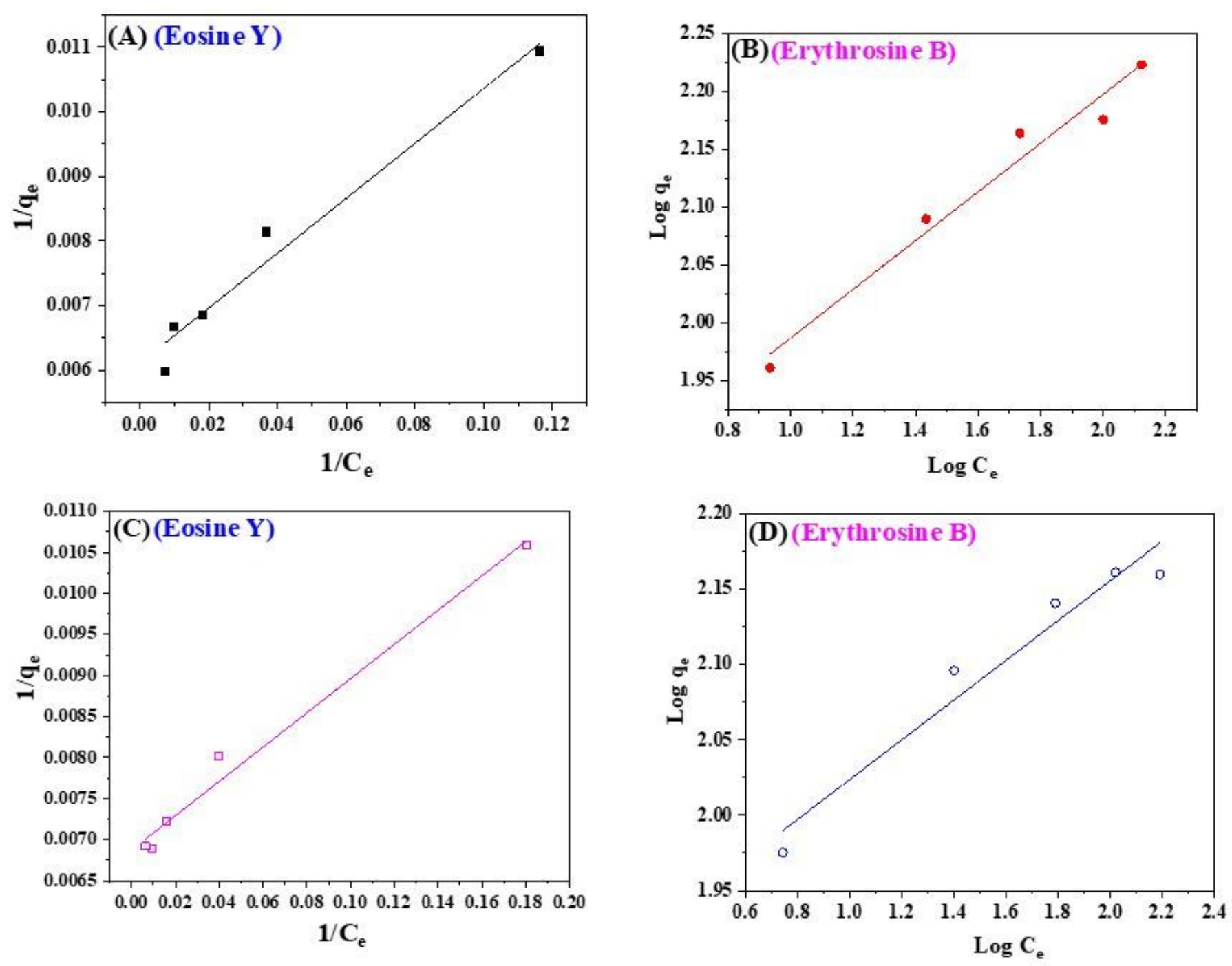

Figure 4

Langmuir (A, C), Freundlich (B, D) models for adsorption of Eo-Y and Er-B by AC-ZnO. 


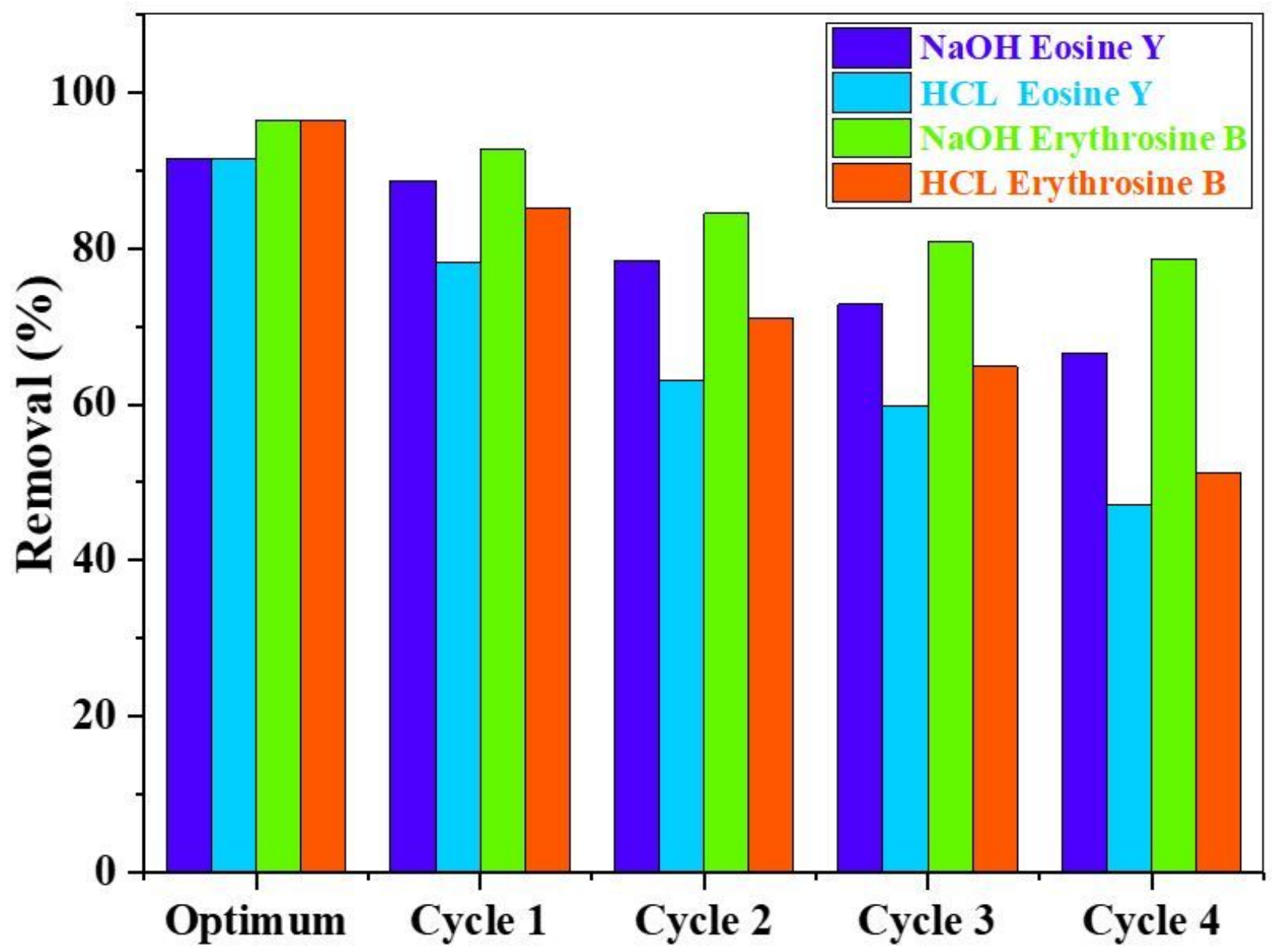

Figure 5

The AC-ZnO recovery in 5 stages.

\section{Supplementary Files}

This is a list of supplementary files associated with this preprint. Click to download.

- Table1.jpg

- Table3.jpg 